\title{
Como avaliar reação de variedades de cana-de-açúcar à Puccinia kuehnii?
}

\author{
Alfredo Seiiti Urashima ${ }^{1} \oplus$, Tatiane de Fátima Mistura ${ }^{1,2} \oplus$, Lis Natali Rodrigues Porto ${ }^{1} \oplus$
}

${ }^{1}$ Universidade Federal de São Carlos, Centro de Ciências Agrárias, Via Anhanguera Km 174, CEP 13600-000 Araras, SP., Brasil. ${ }^{2}$ Parte da dissertação junto a PGPVBA/UFSCar Centro de Ciências Agrárias, Via Anhanguera Km 174, CEP 13600-000 Araras, SP, Brasil.

Autor para correspondência: Alfredo Seiiti Urashima (alfredo.urashima@ufscar.br)

Data de chegada: 28/08/2017. Aceito para publicação em: 04/02/2019

\section{RESUMO}

Urashima, A.S.; Mistura, T.F.; Porto, L.N.R. Como avaliar reação de variedades de cana-de-açúcar à Puccinia kuehnii? Summa Phytopathologica, v.45, n.4, p.387-392, 2019.

A ferrugem alaranjada (Puccinia kuehnii) tem prejudicado a produtividade da cana-de-açúcar no Brasil. O uso de variedades resistentes é o melhor método de controle da doença. No entanto, o sucesso dessa medida está intimamente ligado à correta avaliação da reação do material e diversidade do patógeno. Escalas de notas da doença e porcentagem de área lesionada são os parâmetros mais empregados para estudar resistência de cana-de-açúcar. Já a diversidade do patógeno é examinada por um conjunto de variedades diferenciadoras, o que ainda não está estabelecido para esse patossistema. Portanto, o presente trabalho estudou diferentes parâmetros para avaliar a reação de variedades comerciais de cana-de-açúcar à $P$. kuehnii. Três isolados do patógeno foram inoculados uma única vez em cinco variedades de cana-de-açúcar e sua reação examinada aos $21,28,35$ e 42 dias após, empregando-se escala de notas. A quantidade e viabilidade de esporos também foram investigadas em dois diferentes ensaios, 42 dias depois da inoculação: primeiro, urediniósporos da RB855156 oriundos de lesões com classificação distintas: nota 2 (resistente) e nota 3 (suscetível); segundo: urediniósporos advindos de lesões com mesma classificação de doença, mas de variedades diferentes: RB855156 (suscetível) e RB975201 (resistente). Dados do presente estudo mostraram que a reação da RB855156 variou em função da época da avaliação, sendo resistente na primeira e suscetível na última. Além disso, viabilidade de urediniósporos foi o parâmetro que conseguiu diferenciar genótipos resistentes dos suscetíveis, sendo superior aos outros parâmetros que vem sendo empregados, como tamanho, abertura de pústulas e quantidade de urediniósporos.

Palavras-chave: ferrugem alaranjada, resistência, urediniósporos, Saccharum

\section{ABSTRACT}

Urashima, A.S.; Mistura, T.F.; Porto, L.N.R. How to assess the reaction of sugarcane varieties to Puccinia kuehnii? Summa Phytopathologica, v.45, n.4, p.387-392, 2019.

Orange rust (Puccinia kuehnii) has impaired sugarcane yield in Brazil. Resistant varieties is the best method to control this disease. Nevertheless, the success of this measure is directly related to the correct evaluation of the material reaction and pathogen diversity. Disease scores and percentage of injured area are the most employed parameters to study resistance in sugarcane. The diversity of the pathogen is examined by a set of differential varieties, which is not established yet for this pathosystem. Therefore, the present study aimed to test different parameters to evaluate the reaction of commercial sugarcane varieties to $P$. kuehnii. Three isolates of the pathogen were employed in a single inoculation into five sugarcane varieties and their reaction was evaluated after $21,28,35$ and 42 days, using a disease score scale. The quantity and viability of uredniospores were also assessed through two different trials, 42 days after inoculation; first trial: urediniospores from RB855156 obtained from lesions with distinct classifications: score 2 (resistant) and score 3 (susceptible); second trial: urediniospores originated from lesions with the same disease classification but from different varieties: RB855156 (susceptible) and RB975201 (resistant). Data of the present study showed that the reaction of RB855156 varied according to date of evaluation since it was resistant in the first and susceptible in the last evaluation. Moreover, the viability of urediniospores was the parameter that could best distinguish between susceptible and resistant genotypes, showing to be superior to the other parameters that have been employed, such as size, sporulating pustules and quantity of urediniospores.

Keywords: orange rust, resistance, urediniospores, Saccharum

A cana-de-açúcar fornece matéria prima para vários produtos de alta importância para a economia brasileira, como açúcar, etanol e bioeletricidade. O açúcar é uma das principais "commodities" do agronegócio brasileiro, sendo o país o líder mundial tanto em sua produção, quanto no cultivo da cana (19). O etanol pode ser considerado uma das principais contribuições brasileiras no combate ao aquecimento global, por ser um combustível renovável que emite menos gases de efeito estufa que o petróleo, um combustível fóssil (25). A bioeletricidade, que pode ser obtida da queima do bagaço da cana, é especialmente interessante para a região Sudeste, onde a colheita da cultura coincide com a época de pouca chuva, a bioeletricidade da cana poupou o equivalente a $14 \%$ da água dos reservatórios de hidrelétricas em 2015 (23). Mas o grande desafio da cana-de-açúcar é atender a demanda por suas matérias primas com o aumento da produtividade, sem avançar para áreas ocupadas por outras culturas ou matas virgens. Dentre os vários fatores que comprometem a produtividade a ferrugem alaranjada é uma das principais.

A ferrugem alaranjada, causada pelo fungo Puccinia kuehnii, reduz o crescimento e o rendimento da cana-de-açúcar devido à diminuição da área fotossintética (26). Essa doença foi relatada pela primeira vez no Brasil em 2009, e três variedades foram identificadas como suscetíveis: SP89-1115, RB72454 e SP84-2025, sendo que a recomendação foi 
interrupção do plantio (5). Em 2009, a área ocupada por essas variedades nos estados de São Paulo, Mato Grosso do Sul e Mato Grosso era de 184.158ha de RB72454, 41.105ha de SP89-1115 e de 25.547ha de SP80-20205, aproximadamente $8,4 \%$ da área cultivada (6). A queda de tonelagem de cana causada pela doença na Austrália em 2000 foi de 38\% na variedade Q124 (16), enquanto na Flórida, as reduções foram de $12 \%$ na quantidade de colmos, $32 \%$ na massa vegetativa, $43 \%$ na tonelada de cana por hectare e $53 \%$ na produção de açúcar (20).

O melhor e mais eficiente método de controle da doença é o uso de variedades resistentes (17), devido ao baixo custo ao produtor e limitar o uso de defensivos agrícolas. No entanto, para que essa medida seja efetiva dois requisitos são imprescindíveis: a correta classificação da reação das variedades e da diversidade do patógeno.

A reação de variedades de cana-de-açúcar às ferrugens pode ser examinada sob duas situações distintas: em nível de campo e em laboratório. Avaliações de campo podem empregar metodologias como escala diagramática, onde a avaliação das reações é feita visualmente, permitindo que um grande número de materiais possa ser avaliado $(1,14)$. Em ensaios de laboratório, um número menor de canas é avaliado, mas com maior aprofundamento, já que existe controle melhor das condições ambientais e menor subjetividade de avaliação das reações, pois imagens digitais da área afetada da doença podem ser tomadas e analisadas (Assess APS press, American Phytopathological Society, St. Paul, MN, USA), bem como abertura e quantidade de urédia (21), e quantidade de pústulas esporulantes (22).

Nessas duas classificações, no entanto, aspectos epidemiológicos importantes não foram abordados. Dentre as variedades de cana-deaçúcar plantadas no Brasil existe uma grande variação no que diz respeito à resistência à $P$. kuehnii $(2,10,15)$. Assim, espera-se uma grande variação na produção de urediniósporos produzidos nas lesões de diversos tamanhos, mas não se conhece seu potencial de urediniósporos originados de diferentes lesões para formar ciclos secundários da doença. Devido à natureza policíclica da doença respostas a esses questionamentos são de suma importância para as estratégias de controle da doença.

A eficiência de variedades resistentes está também diretamente relacionada ao conhecimento da diversidade do patógeno. Um dos métodos mais empregados para se investigar esse aspecto é pela existência de raças fisiológicas, determinada pela resposta do patógeno em uma série de variedades diferenciadoras (3). Existência de raças em P. kuehnii tem sido aventada desde a primeira epidemia da doença (17), mas sem uma prova inequívoca de sua existência, sendo a inexistência de variedades diferenciadoras uma das principais causas. Assim, um dos passos primordiais para se determinar a diversidade do patógeno com segurança é a seleção de variedades para compor esse conjunto de diferenciadoras.

Pelo exposto, o presente trabalho estudou diferentes parâmetros para examinar a reação de variedades comerciais de cana-de-açúcar à $P$. kuehnii.

\section{MATERIAL E MÉTODOS}

\section{Hospedeiro}

Gemas individuais das variedades de cana-de-açúcar SP89-1115, RB855156, RB867515, RB935744, RB975201 foram plantadas em copos plásticos de $250 \mathrm{~mL}$ com substrato $(33 \%$ de solo de mata + $33 \%$ de esterco bovino $+33 \%$ de vermiculita; acrescido de $1 \mathrm{~g} . \mathrm{L}^{-1}$ de fertilizante 10-10-10) e mantidas em casa de vegetação até atingirem
3 a 4 folhas. Essas variedades foram selecionadas por apresentarem reações diferentes a isolados de $P$. kuehnii (24).

\section{Patógeno}

O isolado SCPK 01-31 foi retirado de folhas com ferrugem alaranjada da variedade SP89-1115, coletado em outubro de 2015 no CCA/UFSCar, e os outros dois isolados SCPK 18-02 e SCPK 18-03, da variedade SP81-3250, coletados em dezembro de 2015 de uma usina de cana em Araras. Essas folhas foram levadas ao laboratório e os urediniósporos de $P$. kuehnii foram identificados pelas características morfológicas descritas por Comstock et al. (11).

\section{Viabilidade dos urediniósporos}

O teste de germinação dos esporos foi feito com $500 \mu \mathrm{L}$ da suspensão de uredinióposoros em água destilada de cada isolado do fungo, o qual foi espalhado em placas de Petri com meio de cultura ágar água, com auxílio de alça de Drigalski triangular de vidro e deixadas sobre a bancada do laboratório em temperatura ambiente por 24 horas. Depois, em quatro campos distintos da placa foram contados 25 esporos de cada campo no microscópio ótico e a viabilidade dos urediniósporos quantificada e posteriormente, transformada em porcentagem de viabilidade dos urediniósporos.

\section{Inoculação}

Com o auxílio de uma escova de cerdas os esporos foram retirados das pústulas e uma suspensão de urediniósporos preparada em um volume de $25 \mathrm{~mL}$ de água destilada. As plantas foram inoculadas com auxílio de um pulverizador manual a uma concentração da suspensão de $10^{5}$ urediniósporos $/ \mathrm{mL}^{-1}$ (21). Em seguida, mantidas dentro de sacos plásticos pretos por 18 horas a $23^{\circ} \mathrm{C}$ para permitir o processo de infecção. Após esse procedimento, as plantas foram retiradas desse ambiente e mantidas em ambiente natural mas protegida de chuva para manter umidade baixa e assim, prevenir novas infecções do fungo.

\section{Delineamento estatístico}

O delineamento estatístico utilizado foi em blocos ao acaso, com quatro repetições, sendo uma planta por repetição, totalizando 4 plantas. Cada experimento foi realizado duas vezes, em dias diferentes.

\section{Avaliação}

A reação das variedades à inoculação de $P$. kuehnii foi examinada aos 21, 28, 35 e 42 dias após inoculação com base na escala de notas proposta por Tai et al. (22), considerando-se a lesão mais frequente. Em que nota $0=$ folhas sem infecção, $1=$ manchas sem esporulação, 2 = pústulas fracamente esporulantes e identificáveis através de lupa de mão, 3 = pústulas pequenas facilmente identificáveis, $4=$ pústulas mais abundantes e largas, 5 = pústulas de tamanho médio distribuídas nas folhas velhas, $6=$ pústulas de tamanho médio, podendo se estender até as folhas menos maduras, $7=$ similar a 6 , mas com as pontas das folhas mortas e secas, 8 = pústulas grandes, coalescentes e densamente coberta de pústulas, $9=$ similar a 8 , mas todas as folhas velhas estavam secas. Depois a média das notas foi calculada a partir de todas as folhas que apresentaram sintomas da doença. $\mathrm{O}$ número de folhas avaliadas foi: RB855156: 6; SP89-1115: 14; RB935744: 9; RB867515: 7 e RB975201: 15.

Para o ensaio de viabilidade e quantidade de urediniósporos foram utilizadas as variedades RB855156 e a RB975201. Nessa última, a quantidade dessas lesões foi mínima, razão de sua classificação como resistente, mas o suficiente para permitir esse tipo de pesquisa. 
Urediniósporos de quatro pústulas por cultivar por reação (nota 2 e 3 ) foram retirados de cada uma das variedades. Dentro da variedade RB855156 foram comparadas as reações 2 e 3 e entre as cultivares apenas a reação 3 , utilizando a escala de notas elaborada por Tai et al. (22). A viabilidade foi determinada pela frequência de esporos germinados (porcentagem) enquanto a quantidade de urediniósporos, pelo número. Os dados de viabilidade e quantidade de urediniósporos foram transformados em $\sqrt{x+0,5}$ e submetidos ao teste de Tukey a 5\% de significância.

\section{RESULTADOS}

Reação de canas-de-açúcar à $P$. kuehnii em diferentes épocas de avaliação

Três padrões distintos de reações foram observados quando três isolados de $P$. kuehnii foram inoculados em cinco variedades de canade-açúcar, em função da época de avaliação (Figura 1). O primeiro, observado na variedade SP89-1115, caracterizou uma reação típica de material suscetível, onde pústulas abundantes, largas, de tamanho médio e distribuído ao longo do limbo foliar foram observadas já na primeira avaliação aos 21 dias e classificada com notas 4 e 5 . Nas avaliações seguintes ( 28 e 35 dias) os sintomas aumentaram, apresentando pústulas de tamanho médio e grandes, coalescentes e início de necrose em áreas densamente cobertas de pústulas, classificadas com notas 7 e 8 . $\mathrm{Na}$ última avaliação (42 dias) a nota máxima foi atingida (9), devido à necrose generalizada das folhas (Figura 1A). Esse tipo de reação foi provocado pelos três isolados do fungo, caracterizando o material como suscetível para todos esses isolados.

Variedades de cana-de-açúcar também apresentaram reação de resistência à $P$. kuehnii, observado nas variedades RB935744, RB867515 e RB975201, e classificada com notas 0 ou 1, independentemente da época de avaliação. Mesmo em caso de avaliação aos 42 dias a nota máxima atingida foi 2 (presença de pústulas fracamente esporulantes), ainda classificada como resistente (Figura 1).

Um tipo de reação não esperada de cana à $P$. kuehnii foi observada na variedade RB855156, onde a reação foi classificada como a de uma variedade resistente (nota 1) quando a avaliação foi feita aos 21 dias e que nas avaliações posteriores, os sintomas de ferrugem aumentaram até atingir notas 3 ou 6, esta observada com isolado ScPk01-31, todas classificadas como a de variedades suscetíveis (Figura 1A). O mesmo padrão de reação da cultivar RB855156 foi observado com os três isolados de P. kuehnii.

\section{Viabilidade e Quantidade de urediniósporos}

A reação peculiar da variedade RB855156 foi investigada com maiores detalhes, examinando-se a quantidade e a viabilidade dos urediniósporos dessa cana quando classificada como resistente (nota
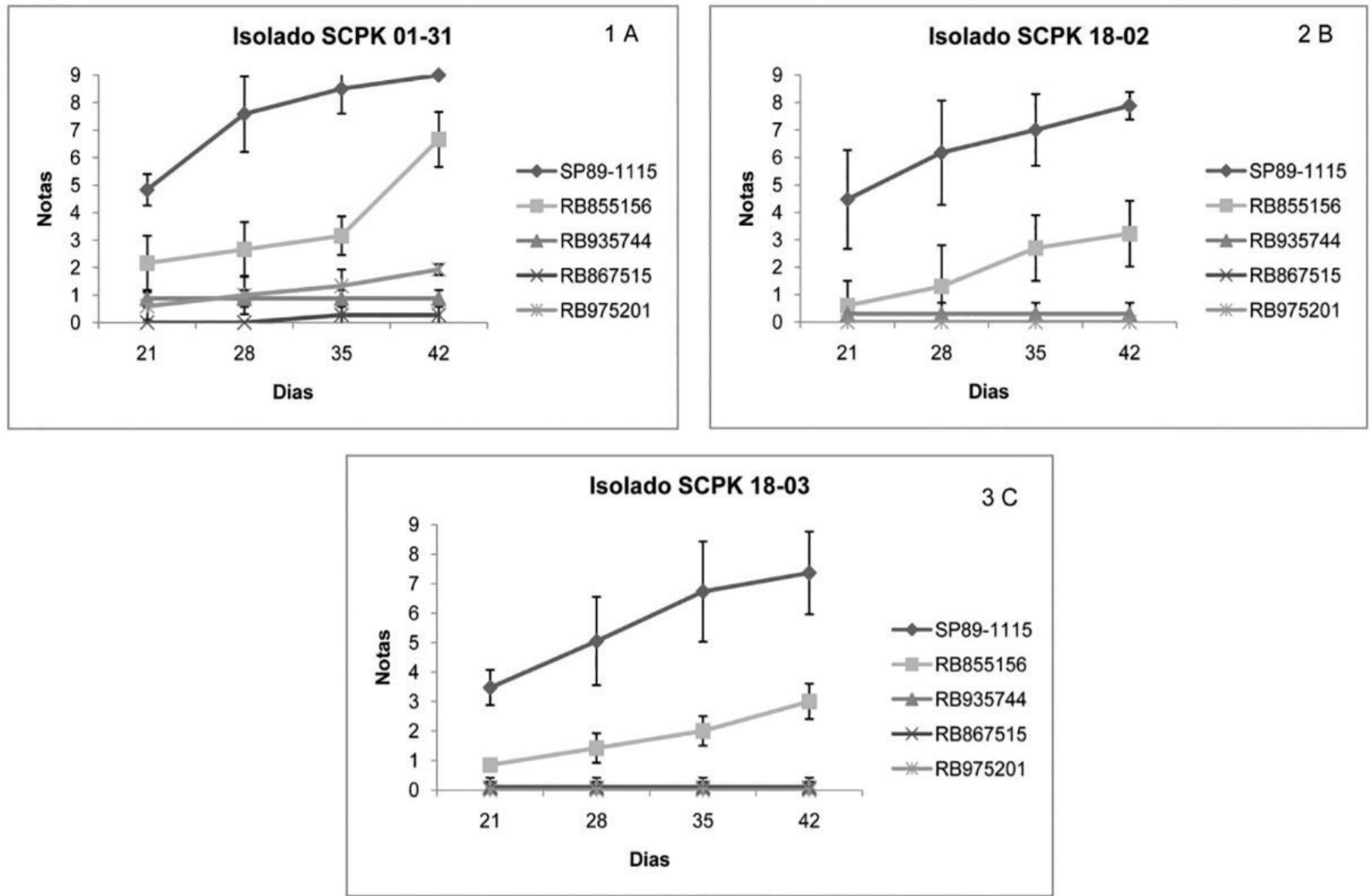

Figura 1. Reação de três variedades de cana-de-açúcar à Puccinia kuehnii, em função da época de avaliação. Nota $0=$ folhas sem infecção, $1=$ manchas sem esporulação, 2 = pústulas fracamente esporulantes e identificáveis através de lupa de mão, 3= pústulas pequenas facilmente identificáveis, $4=$ pústulas mais abundantes e largas, $5=$ pústulas de tamanho médio distribuídas nas folhas velhas, $6=$ pústulas de tamanho médio, podendo se estender até as folhas menos maduras, $7=$ similar a 6 , mas com as pontas das folhas mortas e secas, $8=$ pústulas grandes, coalescentes e densamente coberta de pústulas, $9=$ similar a 8 , mas todas as folhas velhas estavam secas. 
2) e suscetível (nota 3). Não foi observada diferença significativa na quantidade de urediniósporos produzidos pelas urédias de nota $2(21,75$ esporos) quando comparada com as de nota 3 (24,50 esporos). No entanto, quando a viabilidade desses urediniósporos foi comparada, esporos produzidos pelas urédias nota 2 (fracamente esporulantes e identificáveis através de lupa) mostraram viabilidade de 4,25\%, significativamente diferentes da viabilidade de urédias nota 3 (pústulas pequenas e facilmente identificáveis) que foi de 26,96\% (Tabela 1).

Tabela 1. Diferentes reações da variedade RB855156 à Puccinia kuehnii medida pela quantidade e viabilidade de urediniósporos.

\begin{tabular}{ccc}
\hline Nota $^{\mathbf{y}}$ & Quantidade & Viabilidade (\%) \\
\hline 2 & $21,75 \mathrm{a}$ & $4,25 \mathrm{~b}$ \\
3 & $24,50 \mathrm{a}$ & $26,96 \mathrm{a}$ \\
\hline $\mathrm{CV}(\%)$ & 20,64 & 35,68 \\
\hline
\end{tabular}

${ }^{y}$ nota 2 - pústulas fracamente esporulantes e identificáveis através de lupa de mão; nota 3 - pústulas pequenas facilmente identificáveis. Médias em cada .coluna seguidas pela mesma letra não diferem entre si pelo teste de Tukey a 5\%

Em outro ensaio foi estudado a quantidade e viabilidade de urediniósporos produzidos em pústulas com mesma classificação (nota 3: pústulas pequenas e facilmente identificáveis), mas de variedades com resistência diferentes, RB855156 (suscetível) e RB975201 (resistente). A quantidade de esporos produzidos não diferiu significativamente entre as duas variedades, 16,75 e 24,40 , respectivamente. Entretanto, quando a viabilidade desses esporos foi comparada, valor significativamente superior foi observado na variedade suscetível (RB855156) com 16,63\% de esporos viáveis, contrastando com $0 \%$ da variedade resistente (RB975201) (Tabela 2).

Tabela 2. Quantidade e viabilidade de urediniósporos em duas variedades de cana-de-açúcar com resistência diferente à Puccinia kuehnii.

\begin{tabular}{ccc}
\hline \multicolumn{3}{c}{ Reação 3 } \\
\hline Quantidade & Viabilidade (\%) \\
\hline RB855156 & $24,40 \mathrm{a}$ & $16,63 \mathrm{a}$ \\
RB975201 $^{\mathrm{w}}$ & $16,75 \mathrm{a}$ & $0,00 \mathrm{~b}$ \\
\hline $\mathrm{CV}(\%)$ & 22,69 & 25,89 \\
\hline
\end{tabular}

${ }^{\mathrm{y}}$ Variedade suscetível; ${ }^{\text {w }}$ Variedade resistente. Médias em cada coluna seguidas pela mesma letra não diferem entre si pelo teste de Tukey a $5 \%$.

Embora, o ensaio comparativo entre quantidade e viabilidade de urediniósporos de diferentes lesões, e entre variedades tenham sido realizados separadamente, os resultados da RB855156 foram similares para a lesão 3 nos dois ensaios. No primeiro, a quantidade de esporos foi 24,50 e no segundo 24,40 . Já a viabilidade foi de 26,96 no primeiro e $16,63 \%$ no segundo ensaio. $\mathrm{O}$ fato que não ter havido diferença entre esses valores para uma mesma variedade é mais um fator que mostra segurança dos dados.

\section{Visualização da reação nota 2 e tipo 3}

Na escala de notas para avaliar a reação da cana-de-açúcar à $P$. kuehnii empregada no presente trabalho (22), a maior dificuldade encontrada foi na diferenciação da reação nota 2 (presença de pústulas fracamente esporulantes) da nota 3 (presença de pústulas pequenas e esparsas, mas facilmente identificáveis). Assim, o software Assess 2.0 foi empregado para medir área lesionada em lesões com nota 2 e nota 3 (Figura 2), pois estas lesões diferenciavam variedades resistentes das suscetíveis (2). A área das lesões variou de 11 a $39 \mathrm{~mm}^{2}$, assim não havendo diferença entre as lesões.

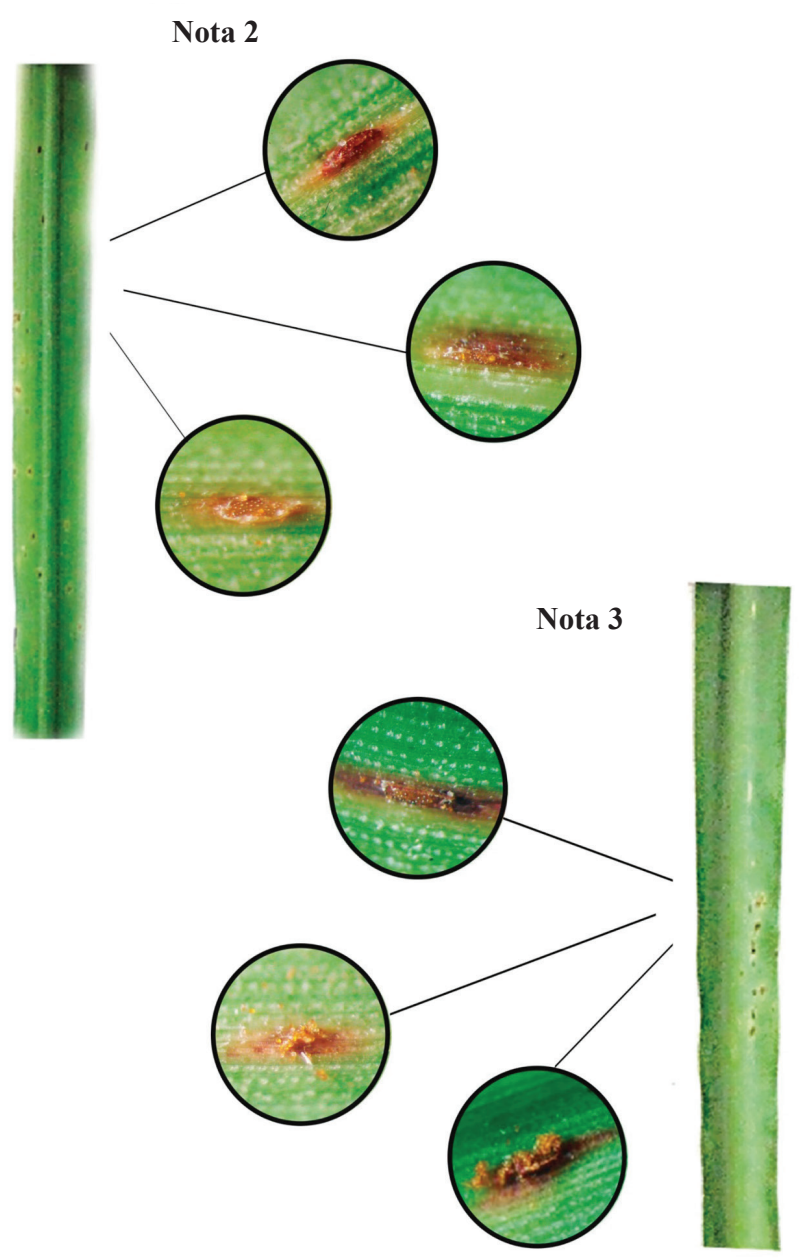

Figura 2. Esporulação de Puccinia kuehnii na variedade RB855156 em função do tamanho das lesões

\section{DISCUSSÃO}

O presente estudo verificou a existência de variedade cuja reação variou em função da época de avaliação. A RB855156 apresentou reação classificada como resistente ao isolado ScPk18-02 e ScPk1803 na avaliação inicial, mas na última se comportou como variedade suscetível (Figura 1).

Identificação de variedades com reação que varia em função da época de avaliação não era esperada e somente foi detectada pelo exame prolongado da interação patógeno-hospedeiro sempre na mesma lesão, ao contrário dos estudos anteriores, onde a severidade 
da doença por longos períodos se baseou na área abaixo da curva de progresso da doença, examinada em folhas diferentes $(2,10,15)$. Embora trabalhosa, identificação de variedades com esse comportamento é de vital importância e servirá para melhorar as estratégias de controle da ferrugem alaranjada.

A estratégia mais empregada de controle da ferrugem alaranjada em todo mundo é o uso de variedades resistentes $(10,17)$. Além da correta avaliação da reação do hospedeiro, a exata noção da diversidade do patógeno também é fundamental (12). E uma das ferramentas para atingir tal objetivo é pela determinação de raças fisiológicas do patógeno, obtida pela reação em um conjunto de variedades diferenciadoras. No patossistema $P$. kuehnii-Saccharum spp. essas variedades ainda não estão estabelecidas, sendo uma das causas pela falta de consenso entre os estudos, com relato de ausência (18) contrastando com presença de raças fisiológicas (24). Nesse sentido, canas com reação definida já nas primeiras avaliações sejam de resistência (RB867515, RB975201 e RB935744) ou suscetibilidade (SP89-1115) seria o primeiro passo para compor esse conjunto de diferenciadoras. Por outro lado, variedades que apresentem reações distintas em função do período de avaliação não poderiam ser empregadas, devido ao risco da avaliação da diversidade do patógeno ser enganosa. Portanto, identificação de variedades com resistência variável em função da época de avaliação, e que é identificada somente em estudos sob condições controladas, é de fundamental importância para o estabelecimento seguro de conjunto de variedades diferenciadoras.

Mesmo que a RB855156 tenha mostrado suscetibilidade nas avaliações finais, sua severidade foi menor que SP89-1115 (Figura 1), razão pela qual foi classificada como intermediária nos estudos de curva de progresso da doença $(2,10)$. Em termos práticos, esse é um dos maiores desafios enfrentados pela indústria canavieira brasileira com a ferrugem alaranjada, qual seja, a existência de variedades com resistência intermediária. A identificação e eliminação das variedades suscetíveis (5) foi prontamente adotada pelo setor como uma das principais medidas de controle da doença, o que pode ser exemplificado pela variedade RB72454, que era a quinta mais importante em 2010 com uma área de 133.514 ha (7) e que em 2013 não mais figurava entre as 10 mais importantes nos estados de São Paulo e Mato Grosso do Sul (8). Entretanto, canas com reação intermediária à ferrugem alaranjada não vão ser eliminadas num futuro próximo, visto que a RB855156 foi a quinta variedade mais cultivada nos estados de S. Paulo e Mato Grosso do Sul em 2015, além de ser a quarta mais empregada em áreas de reforma (9), demonstrando sua importância também nos anos vindouros. Assim, em anos favoráveis às epidemias de ferrugem alaranjada, elevados danos à produtividade podem ocorrer e adoção do uso de proteção química entre as estratégias de controle da doença tem que ser considerada.

Outro dado importante observado no presente trabalho foi que viabilidade de urediniósporos se mostrou um eficiente parâmetro para diferenciar genótipos resistentes dos suscetíveis. Estudo anterior empregou capacidade de esporulação das pústulas para diferenciar materiais resistentes dos suscetíveis (3). No entanto, materiais resistentes também produziram urédias que esporularam no presente estudo (Tabela 2), mostrando que diferenciação de genótipos pelo tamanho e abertura de pústulas (22) pode não ser o parâmetro mais adequado para classificação de variedades. Igual quantidade de urediniósporos era esperada entre variedades com a mesma classificação na escala de notas, já que essa categorização foi baseada no tamanho das pústulas. Esses dados são consistentes com os encontrados na ferrugem da folha do trigo, causada pela $P$. triticina, onde a produção de esporos por lesão esteve intimamente ligada ao tamanho da lesão e a produção de esporos por unidade de tecido esporulante (4). O mesmo foi verificado com a ferrugem marrom da cana-de-açúcar ( $P$. melanocephala) em Louisiana, Estados Unidos, com pouca diferença no tamanho da lesão entre as variedades suscetíveis e resistentes (13). Desse modo, resultados do presente trabalho mostraram que a viabilidade dos urediniósporos de uma variedade resistente (RB975201) foi significativamente menor que a de uma cana suscetível (RB855156) (Tabela 2).

Diferença na viabilidade de esporos produzidas por urédias de tamanho similar mas de genótipo com resistência diferente tem grande implicação no aspecto epidemiológica da doença. Por ser uma doença policíclica, epidemias de ferrugem está intimamente ligado com o número de ciclos secundários formados durante a safra agrícola. Assim, análise da viabilidade vai mostrar urediniósporos que não tem capacidade de formar ciclos secundários, demonstrando que o material é resistente mesmo com que apresente sintomas da ferrugem, que foi o caso observado na variedade RB975201, mesmo que esse tenha produzido pústulas esporulantes, tal qual a RB855156.

Resultados do presente trabalho demonstraram que viabilidade de urediniósporos também tem que ser avaliado na seleção de conjunto de variedades diferenciadoras, pois foi capaz de diferenciar genótipos que produziram o mesmo tipo de sintomas ou mesmo variações tênues dentro de uma mesma variedade (Tabela 1). Mesmo que o número de esporos seja indistinguível entre pústulas fracamente esporulantes (nota 2) e pústulas pequenas facilmente identificáveis (nota 3 ), fazendo com que mesma quantidade de urediniósporos sejam formados, pois os dois tipos de lesões possuíam áreas cloróticas/necróticas de igual tamanho, com a única diferença da existência de uma fina película cobrindo a pústula da lesão classificada como nota 2 (Figura 2).

\section{AGRADECIMENTOS}

O presente trabalho foi realizado com apoio da Coordenação de Aperfeiçoamento de Pessoal de Nível Superior - Brasil (CAPES) - Código de Financiamento 001 e ao Programa de Melhoramento Genético da Cana-de-Açúcar do Centro de Ciências Agrárias (PMGCAUFSCAR/CCA)

\section{REFERÊNCIAS}

1. Amorim, L.; Bergamin Filho, A.; Sanguino, A.; Cardoso, C.O.N.; Moraes, V.A.; Fernandes, C.R. Metodologia de avaliação de ferrugem da canade-açúcar (Puccinia melanocephala). Boletim Técnico Copersucar: São Paulo, v.39, p.13-16, 1987.

2. Araújo, K.L.; Canteri, M.G.; Gilio, T.A.S.; Neubauer, R.A.; Sanches P.B.; Sumida, S.H.; Giglioti, E.A.Resistência Genotípica e monitoramento da favorabilidade para ocorrência da ferrugem alaranjada da cana-de-açúcar. Summa Phytopathologica, Botucatu, v.39, n.4, p.271-275, 2013.

3. Asnaghi, C.; D’Hont, A.; Glaszmann, J.C.; Rott, P. Resistance of sugarcane cultivar R570 to Puccinia melanocephala isolates from different geographic locations. Plant Disease, Saint Paul, v.85, n.3, p.282-286, 2001.

4. Azzimonti, G.; Lannou, C.; Sache, I.; Goyeau H. Components of quantitative resistance to leaf rust in wheat cultivars: diversity, variability and specificity. Plant Pathology, London, v.62, n.5, p.970-981, 2013.

5. Barbasso, D.; Jordão, H.; Maccheroni, W.; Boldini, J.; Bressani, J. First report of Puccinia kuehnii, causal agent of orange rust of sugarcane, in Brazil. Plant Disease, Saint Paul, v.94, n.9, p.1170, 2010.

6. Chapola, R.G.; Hoffmann, H.P.; Bassinelo, A.I.; Fernandes Jr, A.R.; Brugnaro, C.; Rosa, J.R.B.F.; Vieira, M.A.S.; Schiavinato, S.R. Censo varietal de cana-de-açúcar de 2009 dos estados de São Paulo, Mato Grosso e Mato Grosso do Sul, STAB, Piracicaba, v.28, n.5, p.34-37, 2010.

7. Chapola, R.G.; Hoffmann, H.P.; Bassinello, A.I.; Fernandes Jr, A.R.; Vieira, 
M.A.S. Censo varietal 2010 de cana-de-açúcar nos estados de São Paulo e Mato Grosso do Sul. STAB, Piracicaba, v.29, n.3, p.42-45, 2011.

8. Chapola, R.G.; Hoffmann, H.P.; Nunes, I.K., Fernandes Jr, A.R.; Cursi, D.E.; Bassinello, A.I. Variedades de cana-de-açúcar mais cultivadas nos estados de São Paulo e Mato Grosso do Sul em 2013. STAB, Piracicaba, v.32, n.5, p.26-30. 2014

9. Chapola, R.G.; Fernandes Jr, A.R.; Cursi, D.E.; Hoffmann, H.P. Censo de variedades de cana-de-açúcar nos estados de São Paulo e Mato Grosso do Sul em 2015. STAB, Piracicaba, v.34, n.5, p.37-39, 2016.

10. Chapola, R.G.; Hoffmann, H.P.; Massola Jr, N.S. Reaction of sugarcane varieties to orange rust (Puccinia kuehnii) and methods for rapid identification of resistant genotypes. Tropical Plant Pathology, Brasília, v.41, p.139-146, 2016b.

11. Comstock, J.C.; Sood, S.G.; Glynn, N.C.; Shine, Jr.J.M.; McKemy, J.M.; Castlebury, L.A. First report of Puccinia kuehnii, causal agent of orange rust of sugarcane, in the United States and Western Hemisphere. Plant Disease, Saint Paul, v.92, n.1, p.175.1-175.1, 2008

12. Correa-Victoria, F.J.; Zeigler, R.S. Pathogenic variability in Pyricularia grisea at a rice blast "hot spot" breeding site in eastern Colombia. Plant Disease, Saint Paul, v.77, n.10, p.1029- 1035, 1993.

13. Hoy, J.W.; Avellaneda, M.C.; Bombecini J. Variability in Puccinia melanocephala pathogenicity and resistance in sugarcane cultivars. Plant Disease, Saint Paul, v.98, n.12, p. 1728-1732, 2014.

14. Klosowski, A.C.; Ruaro, L.; Bespalhok Filho, J.C.; Mio, L.L.M. Proposta e validação de escala para a ferrugem alaranjada da cana-de-açúcar. Tropical Plant Pathology, Brasília, v.38, n.2, p.166-171, 2013.

15. Klosowski, A.C.; Bespalhok Filho J.C.; Ruaro, L.; Fragoso R.B.; May de Mio, L.L. Reação de cultivares e época de avaliação da ferrugem alaranjada da cana-de-açúcar. Bioscience Journal, Uberlância, v.31, n.2, p.489-498, 2015.

16. Magarey, R.C.; Neilsen, W.A.; Bull, J.I. The effect of orange rust on sugarcane yield in breeding selection trials in Central Queensland: 1999-2001. Proceedings of the Australian Society Sugar Cane Technology, Brisbane, v. 26, p.1-6, 2004
17. Magarey, R.; Willcox, T.; Croft, B.; Cordingley, A. Orange rust, a major pathogen affecting crops of Q124 in Queensland in 2000. Proceedings of the Australian Society Sugar Cane Technology, Brisbane, v. 23, p.274280, 2001.

18. Moreira, A.S. Ferrugem alaranjada da cana-de-açúcar no Brasil: estudo de populações do patógeno e comportamento varietal. 2013. 87f. Tese (Doutorado em Fitopatologia) - Escola Superior de Agricultura "Luiz de Queiroz" - Universidade de São Paulo, Piracicaba.

19. Perfect Insider. 2015. Top 10 largest sugarcane-producing countries. Online: http://www.perfectinsider.com/top-10-largest-sugarcane-producing-countries/ Acesso em 01/06/2019.

20. Raid, R.N.; Comstock, J.C.; Glynn, N. Yield loss incited by orange rust (Puccinia kuehnii) on a highly susceptible sugarcane cultivar in Florida. Phytopathology, Saint Paul, v.100, pg.S106, 2010.

21. Sood, S.G.; Comstock J.C.; Glynn N.C. Leaf whorl inoculation method for screening sugarcane rust resistance. Plant Disease, Saint Paul, v.93, n.12, p.1335-1340, 2009 .

22. Tai, P.Y.P.; Miller, J.D.; Dean, J.L. Inheritance of resistance to rust in sugarcane. Field Crops Research, Amsterdam, v.4, p.261-268, 1981.

23. Unica, União da Indústria da Cana-de-açúcar (2016). Bioeletricidade da cana poupa o equivalente a $14 \%$ da água em reservatórios de hidrelétricas. São Paulo. Disponível em: http://www.unica.com.br/ noticia/2906366292038151244/bioeletricidade-da-cana-poupa-o-equivalente-a-14-por-cento-da-agua-em-reservatorios-de-hidreletricas/. Acesso em 03/06/2019.

24. Urashima, A.S.; Sakuno, C.; Piotto, F. Physiologic races explained the recente outbreaks of orange rust disease on major sugarcane cultivars in Brazil. Phytopathology, Saint Paul, v.104, suppl. 3, p.S3.121, 2014.

25. Weiner, R.; Clingan, G. Brazil is zooming ahead on ethanol. The Miami Herald. Posted 09 August 2012.

26. Zhao, D.; Glynn, N.C.; Glaz, B.; Comstock, J.C.; Sood, S. Orange rust effects on leaf photosynthesis and related characters of sugarcane. Plant Disease, Saint Paul, v.95, n.6, p.640-647, 2011. 